Brigitte Maréchal (éd.), L'Islam et les musulmans dans

l'Europe élargie : radioscopie. A Guidebook on Islam and Muslims in the Wide Contemporary Europe

Louvain-La-Neuve, Bruylant-Academia, 2000, 177 p. (bibliogr., tablx., graphiques)

\title{
Nikola Tietze
}

\section{(2) OpenEdition}

Édition électronique

URL : http://journals.openedition.org/assr/969

DOI : $10.4000 /$ assr.969

ISSN : $1777-5825$

Éditeur

Éditions de l'EHESS

Édition imprimée

Date de publication : 1 octobre 2003

Pagination : 63-170

ISBN : 2-222-96739-2

ISSN : 0335-5985

\section{Référence électronique}

Nikola Tietze, «Brigitte Maréchal (éd.), L'Islam et les musulmans dans l'Europe élargie : radioscopie. A

Guidebook on Islam and Muslims in the Wide Contemporary Europe ", Archives de sciences sociales des religions [En ligne], 124 | octobre - décembre 2003, document 124.67, mis en ligne le 25 octobre 2005 consulté le 24 septembre 2020. URL : http://journals.openedition.org/assr/969 ; DOI : https://doi.org/ 10.4000/assr.969 
principaux acteurs. La citoyenneté devient alors aussi bien culturelle que politique (pp. 137140). Cette nouvelle gestion du pluralisme s'appuie sur une société civile, troisième voie entre l'État et le marché. L'A. y consacre tout le deuxième chapitre mais aussi une partie du quatrième où, analysant les pratiques religieuses des immigrants des grandes métropoles urbaines comme Chicago, New York et Los Angeles, il compare les stratégies mixtes des Sikhs, des Iraniens chiites et des Mexicains, les premiers, fidèles à leur tradition religieuse, les seconds, alliant référence musulmane aux choix séculiers. La société civile apparaît ainsi comme un espace de négociation où des groupes variés, religieux ou non, entrent en compétition pour une redéfinition des valeurs, utilisant leur potentiel réciproque.

L'ouvrage s'appuie sur une bonne connaissance des récents travaux sur l'immigration étrangère depuis 1965 (voir chap. 3) démontrant ainsi la variété et la complexité du groupe asiatique où l'on a tendance à oublier les Indiens, les Pakistanais et les Iraniens. Réapparaissent ainsi les fractures de classe et de race qu'illustre le cas des élites iraniennes et arabes d'origine musulmane peu enclines à se confondre avec l'islam afro-américain.

Le dernier chapitre est consacré au rôle des médias, à leur fonction sociale d'hypervisualisation et à l'influence des Web religieux au sein de la culture populaire. Cette approche apparaît toutefois un peu excentrique par rapport au thème central d'un ouvrage qui constitue un défi pour les Cours de justice, les écoles, les agences gouvernementales et les citoyens américains. Il interpelle aussi l'Europe plurielle de demain.

\section{Chantal Saint-Blancat.}

L'Islam et les musulmans dans l'Europe élargie : radioscopie. A Guidebook on Islam and Muslims in the Wide Contemporary Europe. Louvain-La-Neuve, Bruylant-Academia, 2000, 177 p. (bibliogr., tablx., graphiques).

Le livre constitue un outil de travail utile et intéressant pour la recherche sur l'islam en Europe. Édité sous forme de fiches quantitatives et qualitatives concernant chaque pays (de l'Union Européenne ainsi que la Bulgarie, la Roumanie, la Pologne et la Hongrie), il offre différentes formes de lecture. Une première permet évidemment de consulter un type de données d'un pays à l'autre ou de se concentrer sur un seul pays afin d'obtenir rapidement un aperçu de ses populations musulmanes ou encore de trouver des entrées pour une étude empirique. On découvre alors la diversité de situations et de réalités sociales ou politiques inattendues, comme par exemple la communauté musulmane relativement vieille (depuis le $\mathrm{XIX}^{\mathrm{e}}$ siècle) des Tatars en Finlande qui bénéficie d'une bonne intégration socio-économique et dont le niveau de formation est particulièrement élevé. Des éléments étonnants ressortent également de la situation portugaise où les organisations musulmanes se sont alliées à la communauté juive dans la discussion sur la liberté religieuse. Le nombre important de musulmans ayant acquis la citoyenneté portugaise (entre 50 et $70 \%$ des musulmans possèdent la nationalité du pays) contraste avec d'autres situations ailleurs en Europe. Chaque fiche a été établie de la même manière et répond à sept intitulés: données démographiques, sociographie religieuse, médias, relations entre l'État et les communautés religieuses, débat et opinion publique, rapports inter-religieux et enfin références bibliographiques significatives. Cet inventaire minutieux auquel ont collaboré 20 auteurs, offre des bases pour établir des comparaisons entre différents pays d'Europe et permet d'aller à l'encontre de beaucoup d'idées reçues sur les populations musulmanes. C'est ainsi que l'on apprend que sur les cinquante écoles musulmanes qui existent en Angleterre, seules deux sont subventionnées par l'État, tandis qu'aux Pays-Bas trente-deux établissements scolaires islamiques bénéficient d'un financement public. La lecture horizontale permet également de saisir des convergences dans l'histoire de l'immigration des différents pays ou dans les débats publics sur l'islam par exemple. Elle peut en outre conduire à construire des typologies à partir des constantes qui apparaissent autour de certains thèmes, comme l'enseignement de l'islam à l'école. L'ensemble des fiches participe à l'européanisation de l'islam et introduit cette tradition religieuse comme un sujet de recherche européen. Il reste à savoir si la majorité des croyants concernés se représente ellemême comme une communauté européenne ou si les différentes organisations, médias et commerces islamiques se perçoivent plutôt comme des acteurs nationaux.

Nikola Tietze. 